\title{
Uso de medicina biorreguladora de sistemas en paciente canino alopécico, asociado a quimioterapia metronómica realizada para el manejo de carcinoma de células hepatoides. Reporte de caso.
}

\author{
Juan Carlos Builes Rodriguez ${ }^{1}$ \\ Corresponding Author: Juan Carlos Builes Rodriguez, cvjuanc@gmail.com \\ 1 cvjuanc@gmail.com
}

\begin{abstract}
Paciente canino macho de 12 años con diagnóstico de carcinoma de células hepatoides, el cual fue sometido a una sesión de quimioterapia metronómica, lo que generó alteración gastroentérica, alopecia generalizada y pérdida de la capacidad visual. Inicialmente se instauró terapia convencional durante cuatro meses sin mejoría evidente, sugiriéndole a la propietaria la eutanasia humanitaria ya que no respondió al tratamiento establecido. Fue sometido a terapia biorreguladora durante un mes donde se notó un evidente y favorable cambio en la salud del paciente ya que mejora su gastroenteropatía, se nota foliculogenesis generalizada y recuperación de su capacidad visual. El paciente actualmente goza de total salud y no requiere medicamentos para su estabilidad física y emocional, además no ha recurrido en las lesiones perianales durante el tiempo de terapia biorreguladora. Este caso muestra como la quimioterapia convencional no es la única opción terapéutica, pues no solo presenta efectos secundarios indeseables, sino que el paciente no tiene la capacidad de autoregulación, diferente a la $\mathrm{MBrS}$ que no solo resolvió los trastornos de la quimioterapia sino que genera sobrevida y bienestar animal, dando un pronóstico favorable al paciente.
\end{abstract}

Keywords: Bioregulatory systems medicine, canine hepatoid cell carcinoma, canine post chemotherapy alopecia, chronic low grade inflammation, case report.

\section{Introduction}

Paciente canino lhasa apso 12 años de edad, color blanco y negro que presentaba masa alrededor del ano y el motivo de consulta era disquecia, tenesmo y lesiones ulcerativas perianales, el paciente fue llevado a un centro veterinario de la ciudad de Medellín donde fue resecada quirúrgicamente la masa, se realizó al mismo tiempo la orquiectomía electiva. El análisis histopatólogico reportó adenocarcinoma de células hepatoides y se sugirió quimioterapia metronómica, la cual, con una sola 
sesión, lo desestabilizó sistémicamente presentando vómito, diarrea, pérdida de la capacidad visual y alopecia generalizada asociados a los efectos secundarios de la misma, teniendo el paciente un pronóstico de reservado a malo. La propietaria decide no someterlo a más sesiones de quimioterapia y resuelve llevarlo al centro veterinario Juan Carlos Builes R para someterlo a bio terapia de medicina bio reguladora de sistemas, donde se realizaron procedimientos de detoxificación, inmunomodulación y soporte a diferentes órganos.

Las neoplasias de glándulas perianales son frecuentes en el perro, especialmente en el macho (5), es una condición que está asociada a pacientes que presentan inflamación crónica de bajo grado ya que la matriz extracelular ha sido polimerizada durante un tiempo tan prolongado que se presenta desdiferenciación nuclear del ADN y por lo tanto la aparición de la neoplasia en el tejido glandular perianal. La literatura veterinaria recomienda tratar el carcinoma de glándula hepatoide invasivo con extirpación quirúrgica agresiva con márgenes adecuados combinada con radioterapia (Turek y Withrow 2013 ) (16), otros autores recomiendan quimioterapia metronómica (Fonseca-Alves et al. 2015 ) (3). La neoplasia es hormonodependiente y el tratamiento indicado, para la mayoría de los casos, es la cirugía del tumor y la castración en el macho. Existe una posibilidad de tratamiento médico con base a implantes de deslorelina, utilizados en la castración química reversible en el perro (Ruano, R. 2018) (15); la tasa de recurrencia de la enfermedad es inferior al 10\% y el carcinoma de la glándula hepatoide es menos común después de la castración (Goldschmidt y Hendrick 2002) (7). Turek y Withrow (2009)(18) refieren que las neoplasias de glándulas hepatoides representan hasta el $85 \%$ de neoplasias en esta región corporal. En caso de recidiva después de la cirugía de extracción del tumor y de la castración, es conveniente descartar un posible hiperadrenocorticismo subyacente (Medleau, L. 2007) (10)

"Este informe de caso sigue las pautas de CARE" (Cita: Riley DS, Barber MS, Kienle GS, et al. Explicación y elaboración de CARE: Pautas de presentación de informes para informes de casos. J Clin Epi 2017 Sep; 89: 218- 235. doi: 10.1016 / jclinepi.2017.04.026).

\title{
Timeline
}

\author{
2019-06-01 - Paciente inicia con lesiones ulcerativas perianales, con manejo convencional que \\ mejora durante el tratamiento pero recurre. Al transcurrir el tiempo se nota \\ nodulación perianal que genera dificultad para defecar \\ 2020-06-30 - Se realizan pruebas paraclínicas para someter al paciente a nodulectomía perianal. Se \\ diagnostica carcinoma de células hepatoides y se instaura una sesión de \\ quimioterapia metronómica. Día 0 de ocho meses (tiempo de recuperación del \\ paciente)
}


Se notan efectos adversos gastroentéricos, tegumentarios y oculares asociados a quimioterapia. La medicación convencional no mejora la condición de vida del paciente y su bienestar emocional es inestable.

Paciente continúa inestable, presenta diarrea y vómito, está decaído e hiporéxico, pérdida total de pelaje aunque no presenta lesiones ulcerativas, pérdida de la capacidad visual y no duerme. Se sugiere eutanasia. Cuatro meses de terapia convencional detoxificación e inmunomodulación en consultorio y medicamentos biorreguladores en casa.

Segunda terapia de nebulización para detoxificar e inmunomodular. Paciente estable físicamente sin alteraciones gastroentéricas y mejoría de capacidad visual. Persiste alopecia y alteración en el sueño.

Finaliza cuarta sesión de detoxificación e inmunomodulación en consultorio. Mejoría total de alteración gastroentérica, mejoría de capacidad visual y empieza foliculogenesis primaria en diferentes áreas del cuerpo. Continua con terapia en casa.

2020-11-30 - Paciente clínicamente sano con pelaje en todo el cuerpo, finaliza terapia en casa, duerme tranquilo y es feliz. No se notan lesiones perianales ni intenta autolesionarse como lo hacía inicialmente.

Paciente con marcada mejoría física y emocional, pelaje abundante en todo el cuerpo, sin alteraciones gastroentéricas, duerme bien y no requiere medicación en casa. Paciente con capacidad de autorregulación y no recurrencia. (Fig. 17) perianales. Se prescribe desparasitación de endo y ectoparásitos. (Fig. 18). Ocho meses de evolución desde la cirugía: 4 de resolución con bioterapia que autorregula y no recurre. 


\section{$\underline{\text { Narrative }}$}

Paciente valorado por lesiones perianales ulcerativas, repetitivas y recurrentes con un año de evolución (Fig. 1) en un centro veterinario de la ciudad de Medellín, se sometió a cirugía de nodulectomía y orquiectomía con la respectiva ayuda diagnóstica (Fig. 2) en junio de 2020, con diagnóstico de carcinoma de células hepatoides ( Fig. 3 ) el cual fue sometido a una sesión de quimioterapia metronómica ( Fig. 4 y 5 ) donde se evidenció, durante las siguientes tres semanas, reacciones adversas severas notándose compromiso de sistema gastroentérico (vómito y diarrea), tegumentario (alopecia generalizada) y pérdida de la capacidad visual, con un plan terapéutico convencional poco favorable para la salud del paciente.

Se realizan ayudas diagnósticas de imagenología con énfasis en tórax ( Fig. 6 ) donde se reporta broncopatía crónica, traqueobronquitis, tórax senil y osteoartrosis de hombro bilateral ( Fig. 7 ). Además se realiza ecografía abdominal ( Fig 8 ) donde se reporta hiperplasia prostática benigna, éstas ayudas se realizan con el fin de identificar posible macrometástasis sin evidencia clara de este hallazgo. La quimioterapia genera efectos adversos tan complejos ( Fig. 9 ) que se sugiere la eutanasia humanitaria debido al deterioro de salud del animal por lo que deciden realizar un nuevo tipo de tratamiento con medicina biorreguladora de sistemas. El paciente ingresó al centro veterinario Juan Carlos Builes R el día 6 de octubre de 2020 ( Fig. 10 ) con sintomatología gastroentérica, disminución de la capacidad visual y alopecia post quimioterapia sin lesiones ulcerativas evidentes y en un alto grado de descompensación sistémica. Se realiza valoración inicial y se diagnostica un síndrome inflamatorio mucocutáneo (SIM) asociado a inflamación crónica de bajo grado (ICBG) con etiología multifactorial, pero se destaca la iatrogenia causada por la quimioterapia aplicada. No se realizan pruebas paraclínicas durante la dinámica del caso clínico ya que la propietaria no las autoriza por factor económico.

Se instauran sesiones semanales de detoxificación profunda con pulsatilla compositum ${ }^{\circledR}$, galium heel ${ }^{\circledR}$ y thyreoidea compositum ${ }^{\circledR}$ vía nebulizada, el glyoxal compositum ${ }^{\circledR}$ vía subcutánea, semanal por cuatro semanas que estimularían el tejido linfoide asociado a mucosas (MALT); la nebulización tendría mayor énfasis en los tejidos linfoides asociados a nariz (NALT), a laringe (LALT) y a bronquios (BALT); además se aplica hidroterapia con cloruro de sodio al $0,9 \%$ lo que involucra a todos los anteriores tejidos más el tejido linfoide asociado a gasteroentérico (GALT), a urinario (UALT), a conjuntival (CALT) y el tegumentario (SALT); la terapia fue constante por parte de la propietaria y se nota lenta evolución ( Fig. 11). Adicionalmente se realizaron nebulizaciones

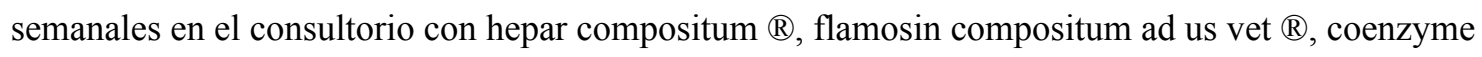
compositum ad us vet ${ }^{\circledR}$, ubichinon compositum ${ }^{\circledR}$, placenta compositum ${ }^{\circledR}$, cutis compositum ${ }^{\circledR}$ y traumel ad us vet ${ }^{\circledR}$; donde se empezaron a ver los resultados en el primer mes de terapia biorreguladora, se nota un paciente con foliculogénesis primaria y secundaria (Fig.12) en diferentes áreas del cuerpo sin evidenciar recurrencias durante el período de tratamiento. 
La terapia domiciliaria (Fig. 13) consistió en administrarle gotas de apis hommacord ${ }^{\circledR}$ (5 gotas cada $8 \mathrm{~h}$ por dos meses), sulfur compositum ${ }^{\circledR}$ tabletas (media tableta vía oral seis veces al día por dos meses) y un simbiótico comercial durante dos meses consecutivos, los cuales mejoran el estado de disbiosis del paciente notándose la rápida y favorable evolución en el sistema gastroentérico y el tegumentario donde se notó pelaje en todas las áreas corporales ( Fig. 14 ), sin lesiones descamativas tan frecuentes en pacientes geriátricos; lo que indica la capacidad de auto regulación y no recurrencia de la enfermedad (Fig. 15). El paciente es valorado en el centro veterinario Juan Carlos Builes tres meses después de la bio terapia inicial donde se notó un paciente clínicamente sano (Fig. 16)

\section{Perspective}

La tutora del paciente describe que el cambio de vida no solo fue para animal sino para la familia en general ya que el simple hecho de no poder dormir, ni ella ni la mascota, generaba un caos intrafamiliar tal que le propusieron a la tutora sacrificarlo para evitar el sufrimiento del animal y no prolongar la enfermedad del mismo. Los diferentes procedimientos terapéuticos convencionales modificaron negativamente el estilo de vida del binomio paciente - tutor hasta que fue sometido a la terapia bio reguladora donde notó, que no solo se estabilizó en su salud, sino que estéticamente mejoró completamente; hecho que generó satisfacción entre las personas del grupo familiar en general y armonía del paciente en particular.

Una de las grandes barreras de este tipo de procedimientos en pacientes oncológicos es el factor económico, ya que la quimioterapia metronómica $(\mathrm{QM})$ no solo era costosa, sino que no garantizaba la total recuperación del animal en cuanto al proceso neoplásico se refería, además era angustiante saber que después de la QM podría presentar gran variedad de efectos adversos tanto desde la salud como desde el punto de vista estético. La familia al no ser de recursos económicos abundantes decide realizar una colecta para poder cancelar la terapia bio reguladora que se hacía menos costosa que la quimioterapia y se presentaba la posibilidad de tener menos efectos adversos y la no recurrencia del proceso neoplásico como ocurrió en este paciente. Adicionalmente el centro veterinario Juan Carlos Builes $\mathrm{R}$ facilitó algunos medicamentos de muestras médicas, para la total aplicación de la terapia biorreguladora, hecho que sumó al proceso de recuperación del animal y por lo que la tutora manifiesta total agradecimiento.

Se debe aclarar que la propietaria manifestó no realizar ayudas diagnósticas de ningún tipo durante el tiempo de bioterapia, ya que había invertido mucho dinero en los procedimientos médicos realizados en otro centro veterinario de la ciudad de Medellín; hecho que dificultó valorar la dinámica de la enfermedad desde una visión paraclínica.

\section{Discussion}


En la medicina biorreguladora de sistemas (MBrS) las matrices extracelular, intracelular, intranuclear e intramitocondrial son el escenario primordial para que actúen las células reparadoras, que cumplirán un papel que hace miles de años vienen cumpliendo: la resolución de la inflamación. Es por esto que se debe visualizar a la matriz extracelular y a la inmunomodulación como dos grandes objetivos terapéuticos para lograr la auto regulación del sistema, evitando así estadíos morbosos como la inflamación crónica de bajo grado (ICBG), enfermedades degenerativas, neoplasias y un sin número de eventos anómalos para el bienestar del paciente.

La matriz extracelular (MEC) se define más comúnmente como el componente no celular del tejido que proporciona soporte estructural tanto bioquímico como esencial para sus componentes celulares. En lugar de servir simplemente como un relleno intercelular, la MEC es un componente fisiológicamente activo del tejido vivo, responsable de la comunicación célula-célula, la adhesión celular y la proliferación celular (4). Se reconoce que la matriz extracelular es un regulador clave de una amplia gama de procesos biológicos celulares, incluida la señalización y la remodelación de tejidos; numerosos estudios bioquímicos y biológicos celulares han documentado las funciones clave que desempeñan las moléculas de la matriz extracelular en el desarrollo embrionario, la remodelación tisular y la enfermedad. (1). Los cambios estructurales de la MEC están relacionados con el mayor o menor tiempo de evolución de la enfermedad y con los cambios asociados con la edad, ya que las proteínas de la MEC tienen consecuencias de gran impacto e incluso tienen el potencial de alterar muchos aspectos relacionados con la homeostasis y al estado de salud (9). Las variaciones adversas observadas en la clínica de pequeños animales, están relacionadas con la mayor o menor alteración que presente la matriz extracelular y la inmunocompetencia del sistema; es por esto que el enfoque biorregulador para la mejoría del paciente fue detoxificar la MEC e inmunomodular el sistema para que se presentara la auto regulación del mismo.

Las metaloproteinasas de la matriz (MMP), también llamadas matrixinas, funcionan en el entorno extracelular de las células y degradan tanto las proteínas de la matriz como las que no lo son. Desempeñan papeles centrales en la morfogénesis, la cicatrización de heridas, la reparación y remodelación de tejidos en respuesta a una lesión, por ejemplo, después de un infarto de miocardio, y en la progresión de enfermedades como el ateroma, la artritis, el cáncer y las úlceras tisulares crónicas. Son proteínas de múltiples dominios y sus actividades están reguladas por inhibidores tisulares de metaloproteinasas (TIMP). (11) Estas endopeptidasas degradan tanto las proteínas de la matriz extracelular (MEC), el colágeno y la fibronectina, como las proteínas que no son MEC, como las citocinas y los factores de crecimiento. En tejido sano, la actividad de MMP es baja o nula, pero aumenta en condiciones patológicas y en procesos fisiológicos de reparación y remodelación.(11).

El manejo terapéutico debe estar fundamentado en la resolución fisiológica del proceso inflamatorio asociado a la modulación de los mediadores específicos de la resolución o metabolomas (resolvinas, protectinas, maresinas, lipoxina A4), es por esto que se debe priorizar en mantener una matriz extracelular despolimerizada, ya que ésta es el campo de juego de los mediadores de la inflamación y la pro resolución para la reparación - regeneración tisular; de ahí la importancia de establecer la 
detoxificación superficial o profunda como una de las herramientas terapéuticas para iniciar el proceso de auto regulación del organismo. Así mismo se debe tener presente la inmunomodulación donde podríamos diferenciarlos, académicamente en dos grupos, a saber:

1. Medicamentos bio reguladores con la capacidad de modular los mediadores pro inflamatorios como la interleucina 1 beta y el factor de necrosis tumoral alfa, factor nuclear Kappa B o estabilizar la membrana de los mastocitos, mecanismos que poseen medicamentos como el traumeel ad us vet ${ }^{\circledR}(\operatorname{Tr} 14)$ y el apis hommacord ${ }^{\circledR}$ quien en su composición posee apis mellifera la cual contiene componentes activos como la melitina, caracterizada por poseer diversos efectos terapéuticos como estabilización de la membrana de mastocitos, modulador del factor nuclear Kappa B y modulador de péptidos antimicrobianos entre otros. Los datos actuales sugieren que la toxina del veneno de abeja (VB) tiene cierto potencial como agente antitumoral, en general, la VB y sus componentes selectivos se consideran agentes prometedores para el tratamiento del cáncer (13). Además, la VB también se ha relacionado con el tratamiento de los efectos secundarios de la quimioterapia contra el cáncer, incluido un estudio en el que se utilizó la farmacopuntura de la VB o la MEL como terapia de control de los síntomas de la neuropatía periférica inducida por la quimioterapia (14) El tratamiento con Tr14 regula varios genes en la familia de las interleucinas que desempeñan un papel clave en la comunicación intercelular y en otras líneas de células inmunes. El Tr14 retrasa y atenúa en un $30-40 \%$ el fuerte aumento ( 600 veces) la expresión de ARNm de IL 1 beta en el periodo de 12 a $24 \mathrm{~h}$ después de la herida. (6)

2. Medicamentos bio reguladores con la capacidad de modular los metabolomas que generan los procesos fisiológicos para la resolución de la inflamación, donde se encuentra el traumel ad us vet con un estudio en genómica que demuestra la acción de este producto en los mediadores específicos de la pro resolución. (6)

La resulómica es un concepto en la medicina no convencional asociado a promover las propiedades fisiológicas que el sistema posee para que él mismo cumpla la diversidad de funciones que se requieren para la reparación- regeneración tisular según sea el caso; de ahí la importancia del uso de medicamentos biorreguladores que ayuden a detoxificar - despolimerizar la matriz extracelular e intranuclear como la pulsatilla compositum ${ }^{\circledR}$, galium heel ${ }^{\circledR}$, thyreoidea compositum ${ }^{\circledR} \mathbf{y}$ Glyoxal compositum ${ }^{\circledR}$. Siguiendo los pilares de la medicina de redes, no solo se debe realizar una adecuada detoxificación matricial, sino que se debe inmunomodular y darle soporte a diferentes órganos que estén comprometidos por la noxa presente.

Los organopreparados suis y los diferentes componentes fitoterapéuticos que poseen medicamentos bioreguladores como la pulsatilla compositum ${ }^{\circledR}$ y el cutis compositum ${ }^{\circledR}$ generan diferentes respuestas en favor de la resolución de la enfermedad. La pulsatilla compositum ${ }^{\circledR}$ presenta dentro de sus componentes organopreparados y el mellilotus oficinalis,el cual tiene diferentes estudios donde se concluye que mejora la apoptosis de los tejidos cerebrales en ratas con isquemia cerebral al disminuir la trombosis cerebral, el estrés oxidativo y los mediadores inflamatorios (8); además se ha 
utilizado tradicionalmente para actividades antiinflamatorias y antiedematosas, alteraciones de la piel, tratamientos antienvejecimiento, como flebotónico, espasmolítico, diurético y sedante(2). El cutis compositum también posee organopreparados suis y un componente fitoterapéutico muy particular llamado Thuja sp el cual tiene propiedades en la foliculogénesis al inducir la fase anagénica en ratones que presentaban telogenia; en un estudio se observó un aumento en el número y tamaño de los folículos pilosos, lo que sirvió como prueba para la inducción de fases anágenas, por lo que se concluye que la Thuja orientalis promueve el crecimiento del cabello al inducir la fase anágena de los folículos pilosos y, por lo tanto, podría ser un agente promotor del crecimiento del cabello.(12)

Los agentes de quimioterapia pueden causar efectos secundarios gastrointestinales (GI) de leves a graves, y los medios eficaces para mitigar estos efectos siguen siendo difíciles de alcanzar. La vincristina es un fármaco quimioterapéutico de uso común con eventos adversos (EA) como letargo, vómitos, diarrea o citopenias que pueden ocurrir en casi el 70\% de los perros tratados; sin embargo, la mayoría de estos EA son de bajo grado. (19) Los efectos adversos relacionados con la quimioterapia siguen siendo una limitación significativa para la intensidad de la dosis, el resultado potencial y la calidad de vida de un paciente con cáncer. Estudios actuales sugieren que el ayuno es un tratamiento razonable a considerar para los EA constitucionales y gastrointestinales asociados con la vincristina en perros de razas grandes. Se ha demostrado que el ayuno reduce los eventos adversos (EA) asociados a la quimioterapia, en parte a través de la reducción del factor de crecimiento similar a la insulina (IGF - 1), y puede inducir un efecto protector sobre las células normales durante el tratamiento con quimioterapia en ratones y personas. (17)

En este caso se notó una marcada inestabilidad sistémica, donde no solo hubo compromiso gastroentérico sino tegumentario, visual y conductual; es importante resaltar que el uso de la medicina biorreguladora de sistemas no solo mejora las alteraciones anteriormente nombradas, sino que evitó la regresión de los efectos adversos y no se evidenció un nuevo crecimiento de las glándulas perianales. Uno de los objetivos de la MBrS fue aliviar y modular el síndrome inflamatorio de mucosas (SIM) que estaba presente por la iatrogenia de la quimioterapia utilizada, donde los parámetros a evaluar para su recuperación fueron la completa mejoría de la hiporexia, la sintomatología gastrointestinal (no vómito, ni reflujo gastroesofágico, ni diarrea), la recuperación tegumentaria con foliculogénesis, donde se notó pelos primarios y secundarios (manto y sub manto) sin recurrencia evidente en el tiempo de terapia; además su condición corporal mejoró significativamente y su estabilidad emocional retornó a lo que era el paciente antes de ser sometido a la quimioterapia.

Finalmente se puede evidenciar que de los 8 meses contabilizados desde junio de 2020 (inicio de cirugía y posterior sesión de quimioterapia) hasta febrero de 2021 (resolución completa de la enfermedad por la MBrS), cuatro de ellos el paciente estuvo bajo el enfoque convencional con los efectos adversos de la quimioterapia y sin solución por parte de los medicamentos convencionales; a diferencia de la terapia biorreguladora realizada en un mes donde se evidenció total estabilización del paciente, los siguientes tres meses fueron de control y mejoría de la condición corporal, estética y conductual.

\section{Conclusion}


Los pacientes con neoplasias presentan una compleja desdiferenciación nuclear lo que hace que éstos difícilmente retornen a un estado de salud total o parcial y más complejo aún es permanecer en un estadío de autoregulación sin recurrencias en la medida que transcurra el tiempo. En este caso se nota como con la medicina biorreguladora de sistemas se puede tener pacientes con un compromiso sistémico muy complejo (carcinoma de células hepatoides) y sin embargo se retornó a la completa homeodinamia pese a su avanzada edad.

El diagnóstico definitivo, la identificación de los sistemas que están involucrados en la alteración del equilibrio sistémico y la estabilidad emocional del paciente y el tutor son piezas claves para constituir e instaurar el adecuado plan terapéutico integrativo. Apoyarse en la detoxificación de las matrices, inmunomodular y dar soporte orgánico a los sistemas que se encuentren comprometidos es clave para obtener resultados clínicos satisfactorios y que el mismo organismo tenga la capacidad de autoregularse que debe ser el objetivo final del médico veterinario con énfasis en pequeños animales.

El impacto médico y emocional que genera este caso no solo aplicaría para este paciente, sino que sería posible transpolar y socializar diferentes conceptos que tienen en común los animales y el hombre para hacer de la medicina el medio idóneo que mejore la calidad de vida en pacientes oncológicos y post quimioterapia. Sería idóneo compartir conocimientos entre la medicina humana y la medicina veterinaria por el bien común de la sociedad.

\section{$\underline{\text { Acknowledgements }}$}

Seré un eterno agradecido de la vida y su creador.

A mi familia que comprende todos los tiempos que no estoy con ellos.

A Nidia la tutora y Peluche el paciente, que serán eternos maestros de enseñanzas diarias y a mi grupo de trabajo del centro veterinario Juan Carlos Builes que son pilares para mi desempeño profesional.

A los médicos que nos acompañan permanentemente en asesorías de la familia Heel vet, Dr. David Quintana y Dra. Mónica Valencia.

\section{$\underline{\text { References }}$}

1 Bachir AI, Horwitz AR, Nelson WJ, Bianchini JM. Actin-based adhesion modules mediate cell interactions with the extracellular matrix and neighboring cells. Cold Spring Harb Perspect Biol.

2017;9 10.1101/cshperspect.a023234

2.Burlando B .; Verotta L .; Cornara L .; Bottini-Massa E .. Monografías de principios herbales . En Principios a base de hierbas en cosméticos. Propiedades y mecanismos de acción ; CRC Press, Taylor \& Francis Group: EE.UU., 2010; págs. 368-370. 
3.Fonseca-Alves CE, Kobayashi PE, Rivera-Calderón LG, Laufer-Amorim R. 2015. Evidence of epithelialmesenchymal transition in canine prostate cancer metastasis. Res Vet Sci. 100:176-181.

4.Frantz C., Stewart K.M., Weaver V.M. The extracellular matrix at a glance. J. Cell Sci. 2010;123:4195-4200. doi: $10.1242 /$ jcs.023820.

5.G. Pisani a, F. Millanta b, D. Lorenzi b, I. Vannozzi c, A. Poli b, Androgen receptor expression in normal, hyperplasticand neoplastic hepatoid glands in the dog

6.Georges St. Laurent III, Bernd Seilheimer, Michael Tackett, Jianhua Zhou, Dmitry Shtokalo, Yuri

Vyatkin, Maxim Ri, Ian Toma, Dan Jones and Timothy A. McCaffrey Deep Sequencing Transcriptome Analysis of Murine Wound Healing: Effects of a Multicomponent, Multitarget Natural Product Therapy-Tr14 Front. Mol.

Biosci., 17 August 2017 | https://doi.org/10.3389/fmolb.2017.00057

7. Goldschmidt MH, Hendrick MJ. 2002. Tumor of the skin and soft tissue. In: Meuten DJ, editor. Tumors in domestic animals (4th ed). St. Louis, Missouri: Elsevier. (IA: ); p. 45-117.

8.Gui-Cun Zhao, Yan-Ling Yuan, Feng-Rong Chai,Fa-Jing Ji Effect of Melilotus officinalis extract on the apoptosis of brain tissues by altering cerebral thrombosis and inflammatory mediators in acute cerebral ischemia. Biomed Pharmacother 2017 May;89:1346-1352.DOI: 10.1016/j.biopha.2017.02.109

9.Helen L. Birch. Extracellular Matrix and Ageing. Subcell Biochem_2018;90:169-190. PMID: 30779010 DOI: $10.1007 / 978-981-13-2835-0 \_7$

10.Medleau, L; Hnilica, KA. Dermatología de pequeños animales. Atlas en color y guía terapéutica. Segunda edición. ISBN edición esp. 978-84-8086-202-8 Elsevier Saunders (2007)

11.Nagase H, Visse R, Murphy G. Structure and function of matrix metalloproteinases and TIMPs. Cardiovasc Res. 2006;69:562-573.

12.Nan-nan Zhang, Dong Ki Park and Hye-Jin Park. Hair growth-promoting activity of hot water extract of Thuja orientalis. BMC Complement Altern Med. 2013; 13: 9. Published online 2013 Jan 10. doi: 10.1186/1472-6882-139

13. Orsolic N. Bee venom in cancer therapy. Cancer Metastasis Rev. 2012; 31:173-194. [PubMed] [Google Scholar]

14.Park JW, Jeon JH, Yoon J, Jung TY, Kwon KR, Cho CK, et al. Effects of sweet bee venom pharmacopuncture treatment for chemotherapy-induced peripheral neuropathy: a case series. Integr. Cancer Ther. 2012; 11:166171. [PubMed] [Google Scholar]

15.Ruano, R. Comportamiento biológico de los tumores según su localización. Capítulo 4. Manual de Oncología para veterinarios clínicos. Como enfrentarse al paciente oncológico. Noemí del Castillo Magán / Ricardo Ruano Barneda. Editorial Servet. (2017)

16. Turek MM, Withrow ST. 2013. Perianal tumors. In: Withrow SJ, Vail DM, Page RL, editors. Small animal clinical oncology. Saint Louis: Elsevier; p. 423-431. 
17.Shay Bracha, Margaret E. Duckett, Kaitlin M. Curran, Haley J. Leeper, Carl E. Ruby. Fasting reduces the incidence of vincristine-associated adverse events in dogs. Vet Comp Oncol. 2021 Mar; 19(1): 61-68.

18. Turek M, Withrow S. 2009. Tumores perianales. En: Withrow S, Vail D (eds). Oncología clínica de pequeños animales. 4 a ed. España: Multimédica Ed Veterinarias. p 492-498.

19. Vail DM. Supporting the veterinary cancer patient on chemotherapy: neutropenia and gastrointestinal toxicity. Top Companion Anim Med. 2009;24:122-124. [PubMed] [Google Scholar]

\section{Attachments}




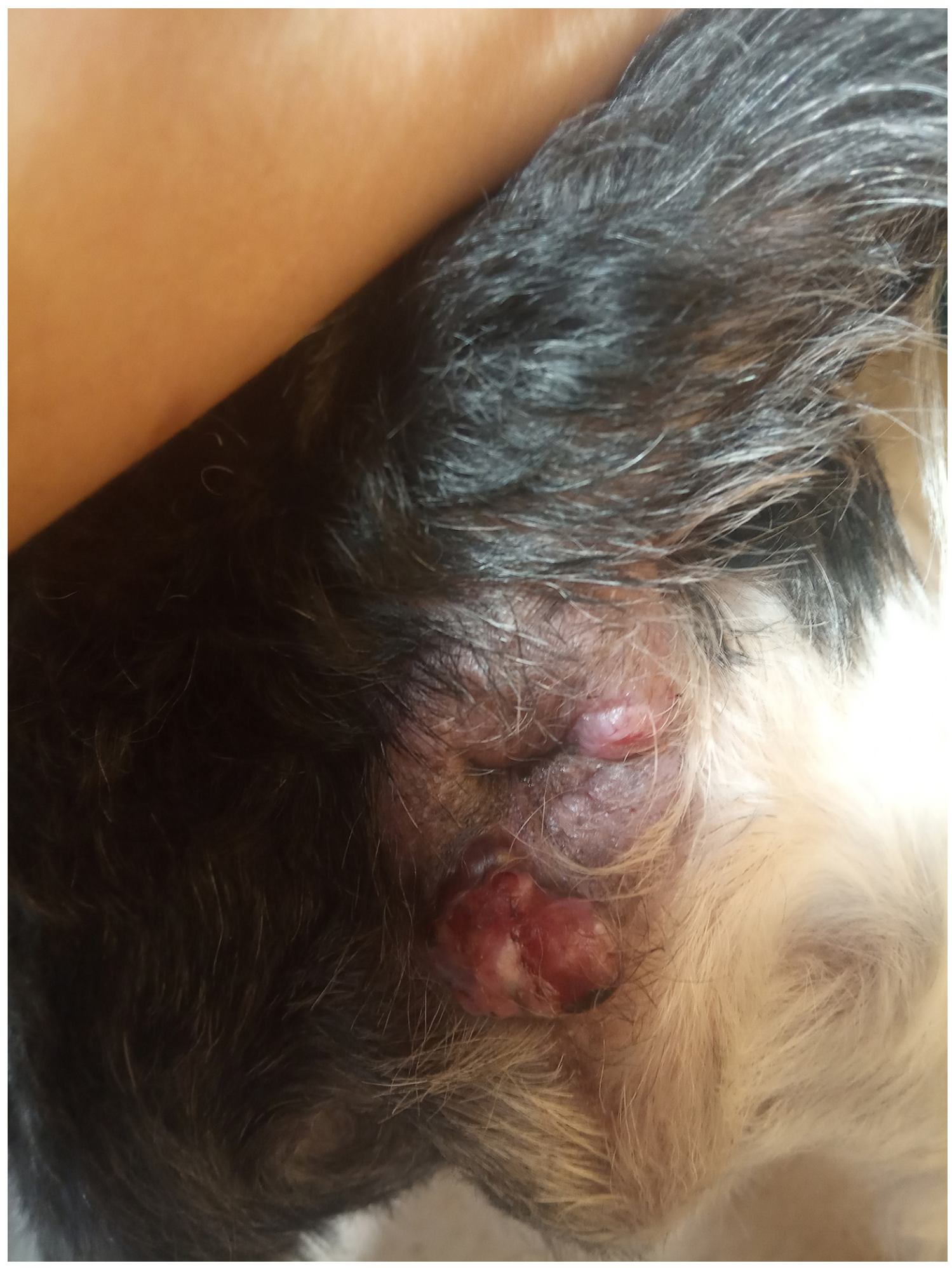

Figura 1. La presencia del carcinoma de células hepatoides es la consecuencia de un proceso inflamatorio crónico de bajo grado. Este tipo de neoplasias es hormono dependiente requiere extirpación quirúrgica y orquiectomía, procedimientos realizados en otro centro veterinario de la ciudad de Medellín. Se observan dos masas perianales de donde se tomaron muestras para estudio histopatológico. 


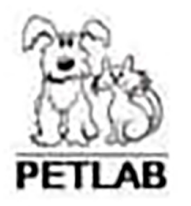

Orden No: 231155

\begin{tabular}{|c|c|c|c|c|c|}
\hline Focha : & $30 / 06 / 2020$ & HC/Ident: & 51 & 81474 & \\
\hline Nombre: & PELUCHE NARANJO & Edad: & 8 & Año(s) & Sexo: $M$ \\
\hline Espocia : & CANINO & Raza : CR & uO & & \\
\hline Propietario: & NIDIA NARANJO & Teléfono: & 0 & & \\
\hline Vetorinario: & CARLOS ALBERTO RESTREPO & Entidad : & LINIC & A VETER & IARLA LA 80 \\
\hline
\end{tabular}

\begin{tabular}{lll}
\hline EXAMEN & RESULTADO & VALORES DE REFERENCIA
\end{tabular}

PANEL BASICO

HEMOGRMMA COMPLETO -

RECUENTO DE GLOBULOS ROJOS:

HEMOGLOBINA $\quad 15,3$

HEMATOCRITO $\quad 45,1$

MCV 75,5

$\begin{array}{ll}\mathrm{MCH} & 25,6\end{array}$

$\mathrm{MICHC} \quad 33,9$

RDW 13,2

PLAQUETAS 441,000

MIPV $\quad 9.6$

LEUCOGRAMA

RECUENTO DE GLOBULOS BLANCOS 6,900

NEUTROFILOS 69

ABS. $\quad 4,76$

EOSINOFILOS 2

ABS 0,13

LINFOCITOS 29

ABS $\quad 2.00$

PROTEINAS PLASIMATICAS $\quad 7.0$

EXTENOIDO HEMOPARASTOS

CREATININA EN SUERO

CREATININA

TRANSAMINASA ALT/GPT

AL.T

970,000

.1

5

9

6

76

13

00

7,0

NO SE OBSERVA

0.67

48,8

\begin{tabular}{|c|c|}
\hline$\times 10^{\circ} 6 \mathrm{ml}$ & $5,5 \cdot 8,5$ \\
\hline gids & $12-18$ \\
\hline$x$ & $37 \cdot 55$ \\
\hline $\mathrm{tL}$ & $60 \cdot \pi$ \\
\hline $\mathrm{pg}$ & $20-25$ \\
\hline g/d & $32 \cdot 36$ \\
\hline$\%$ & $12-16$ \\
\hline$\times 10^{\circ} 3 \mathrm{ml}$ & $200-500$ \\
\hline $\mathrm{IL}$ & $5,8-9,2$ \\
\hline . & - \\
\hline$\times 10^{\circ} 3 / \mathrm{ml}$ & Q. 17 \\
\hline \multirow[t]{2}{*}{$\%$} & $60 \cdot 77$ \\
\hline & $3 \cdot 11,5$ \\
\hline \multirow[t]{2}{*}{$\%$} & $2 \cdot 10$ \\
\hline & $0,1-1,25$ \\
\hline \multirow[t]{2}{*}{$\%$} & $12 \cdot 30$ \\
\hline & $1 \cdot 4,8$ \\
\hline 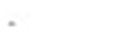 & $6 \cdot 8$ \\
\hline \multirow[t]{2}{*}{. } & - \\
\hline & - \\
\hline \multirow[t]{3}{*}{ mgla } & $0.5 \cdot 1.6$ \\
\hline & $\cdot$ \\
\hline & $8,2 \cdot 57,3$ \\
\hline
\end{tabular}

Transweraal 33 sur a 22-25 La Magnolis

Telefono (4) 2701108 - Envigado - Antioquia

Pagina 2 os 3

Figura 2. Pruebas paraclínicas para valorar línea roja y blanca las cuales no presentaban alteraciones aparentes. Pruebas realizadas en un centro veterinario de la ciudad de Medellín. Se valora ALT y creatinina las cuales están en rango fisiológico, lo cual indica que es un paciente apto para la nodulectomia perianal, realizada en otro centro veterinario de la ciudad de Medellín 


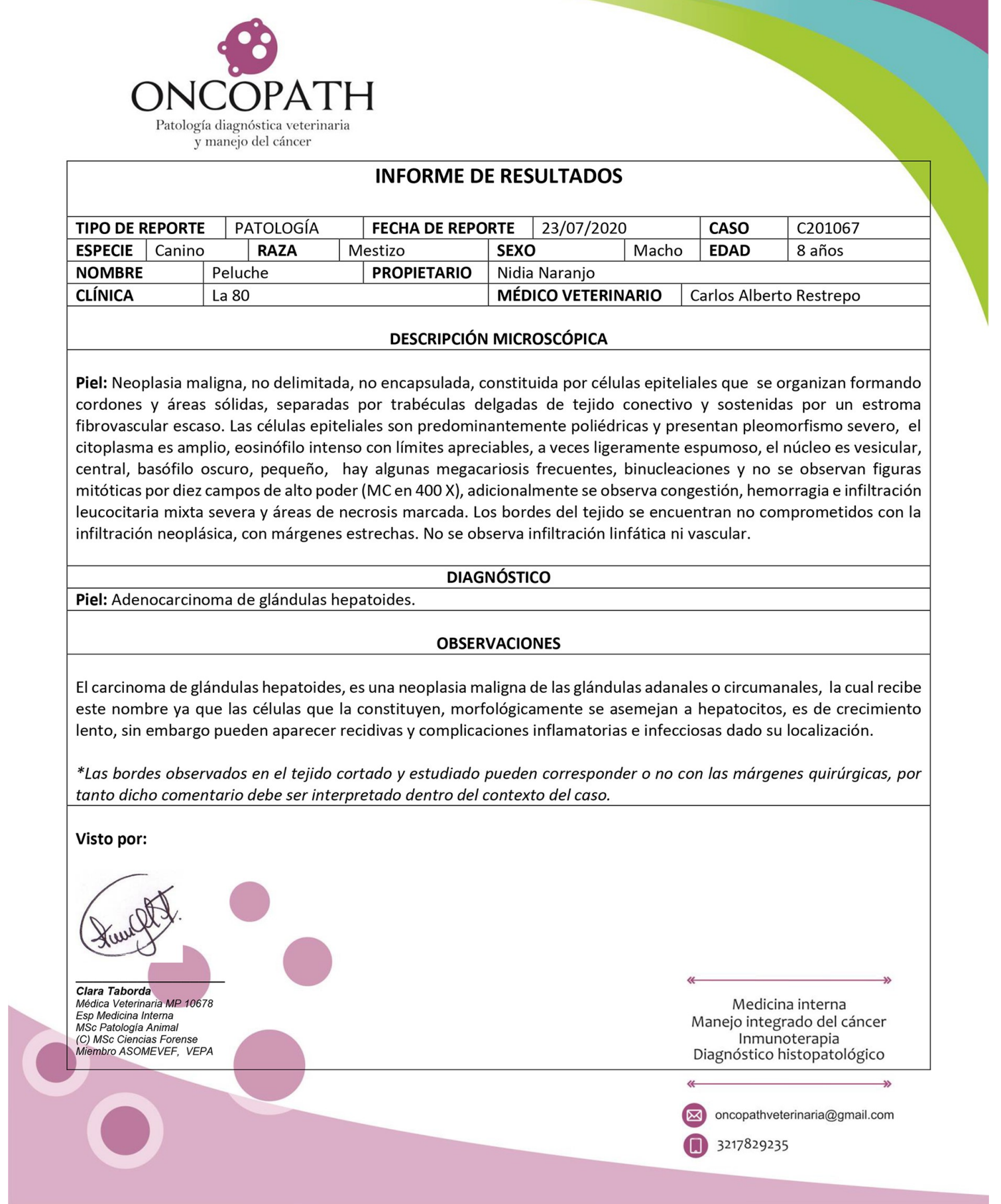

Figura 3. Estudio histopatológico donde se realiza el diagnóstico definitivo de carcinoma de células hepatoides. 


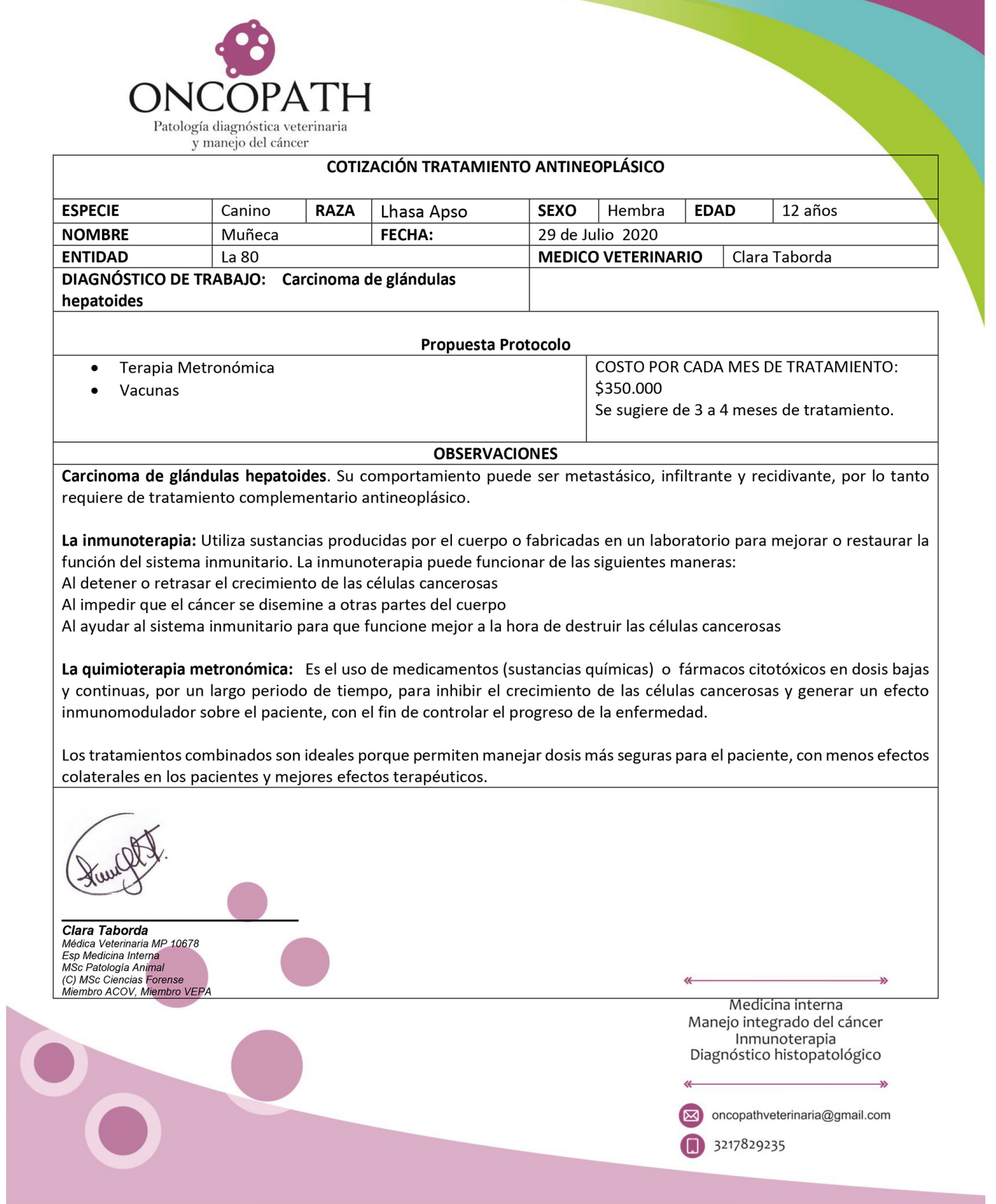

Figura 4. Se da una primera opción de quimioterapia para el tratamiento del carcinoma de glándulas hepatoides con su respectivo costo. Se decide optar por esta terapia, la cual incluye vincristina pero no se obtienen datos especificos del centro veterinario que la realizó. 


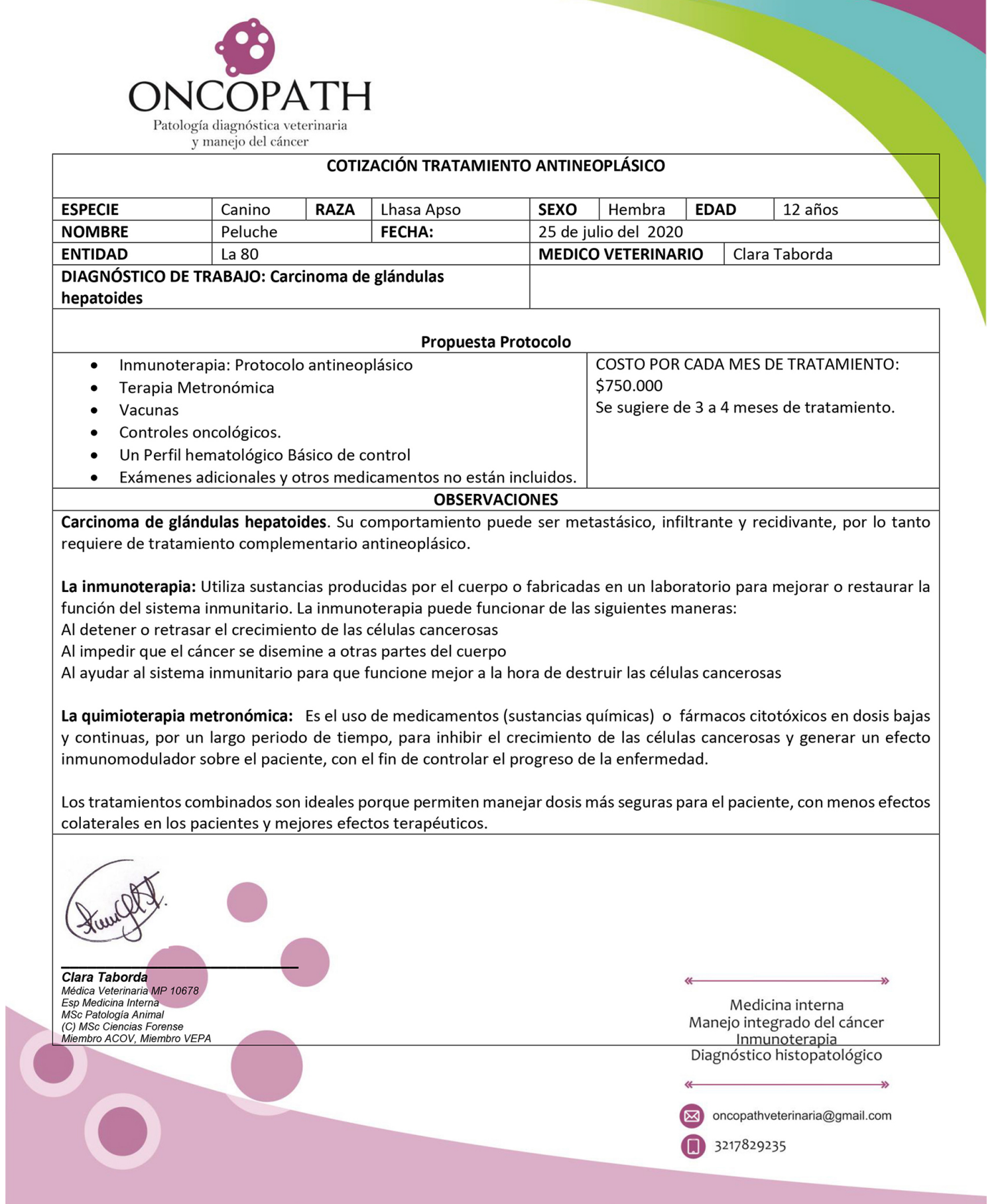

Figura 5. Segunda opción de quimioterapia sugerida por la médica veterinaria con énfasis en oncología, pero no se realiza esta terapia por costos y posibles efectos adversos. 


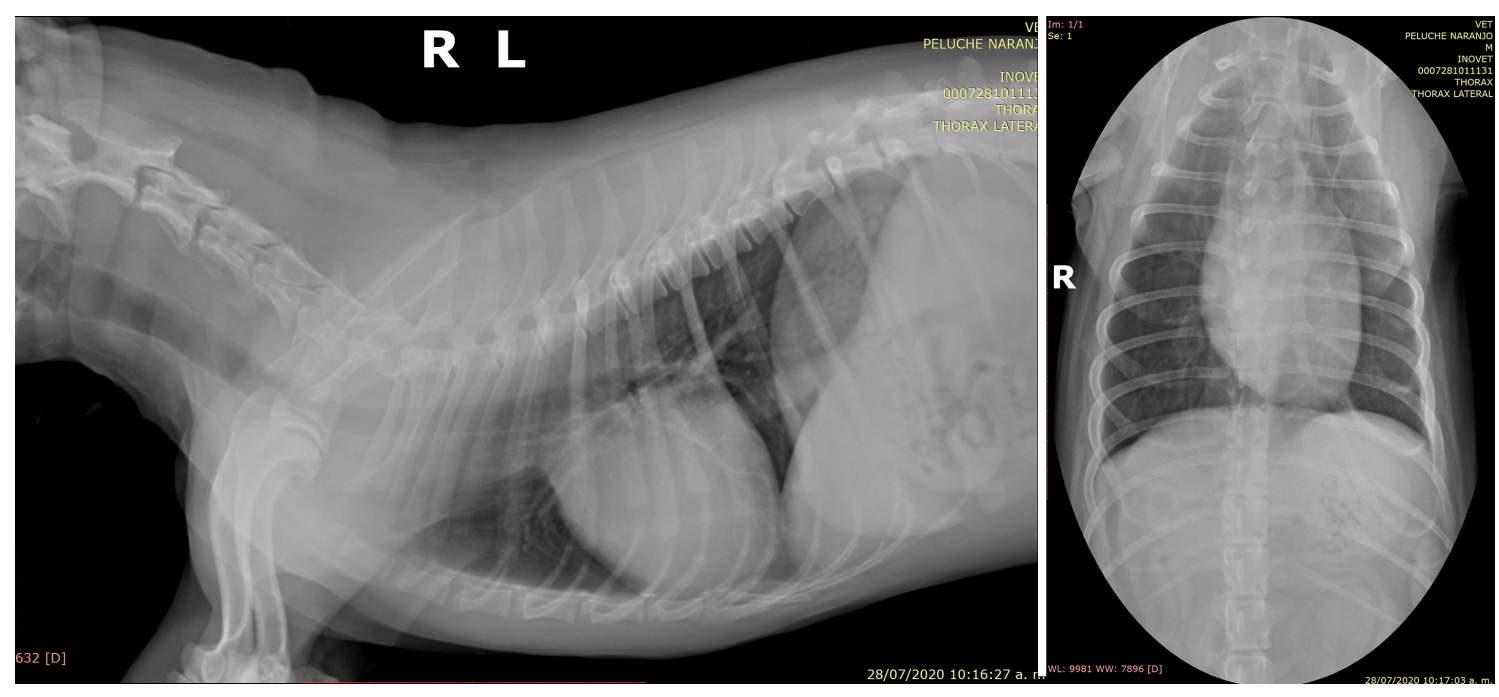

Figura 6. Radiografía ortogonal de tórax para identificar posible macrometástasis secundaria al carcinoma de células hepatoides. Ayuda imagenológica obtenida en otro centro veterinario de la ciudad de Medellín. 


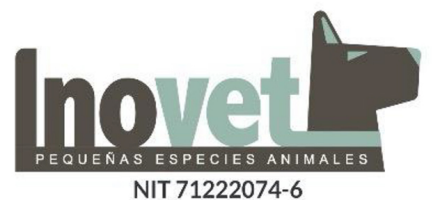

INFORME RADIOLÓGICO

FECHA: Julio 28 de 2020

NOMBRE: Peluche Naranjo

RAZA: Canino (Criollo)

EDAD: 10 Años

PROPIETARIO: Nidia Naranjo

ESTUDIO REALIZADO: Estudio Radiológico Lateral y ventrodorsal de tórax.

REMITENTE: Vet Clínica Veterinaria.

\section{DESCRIPCIÓN RADIOLOGICA:}

Tráquea de bordes regulares y definidos con aumento de la densidad de sus bordes, conservada en diámetro y posición. Silueta cardiaca con bordes regulares y definidos, índice cardiovertebral $9.5 \mathrm{CV}$, sin agrandamientos camerales aparentes, contacto cardioesternal conservado. Patrón pulmonar mixto bronco-intersticial, mineralización de las paredes bronquiales y presencia de escasos infiltrados peribronquiales de distribución difusa. Sin evidencia de masa, nódulos y/o efusión pleural. Reacción osteofitica en el aspecto ventral de ambas cabezas humerales.

\section{HALLAZGOS RADIOLOGICOS SUGERENTES:}

Broncopatía crónica.

Traqueobronquitis.

Tórax senil.

Osteoartrosis de hombro bilateral.

Lotolime Rúo Ruiz

CATALINA RÚA RUIZ

Mv, Esp UBA, Msc UdeA

MP 13262

NOTA: Los diagnósticos diferenciales se listan en orden de importancia según los hallazgos radiológicos, se recomienda al médico remitente corroborar o descartarlos de acuerdo con la anamnesis, examen clínico y otros exámenes paraclínicos del paciente.

Carrera 77a Nro. 49 - 15 •Cel: 3015963274 • inovetdiagnostico@gmail.com

Medellín - Colombia

Figura 7. Descripción del informe radiológico donde se identifican hallazgos propios de la edad del paciente pero no reportan metástasis pulmonar. Ayuda diagnóstica realizada en otro centro veterinario. 


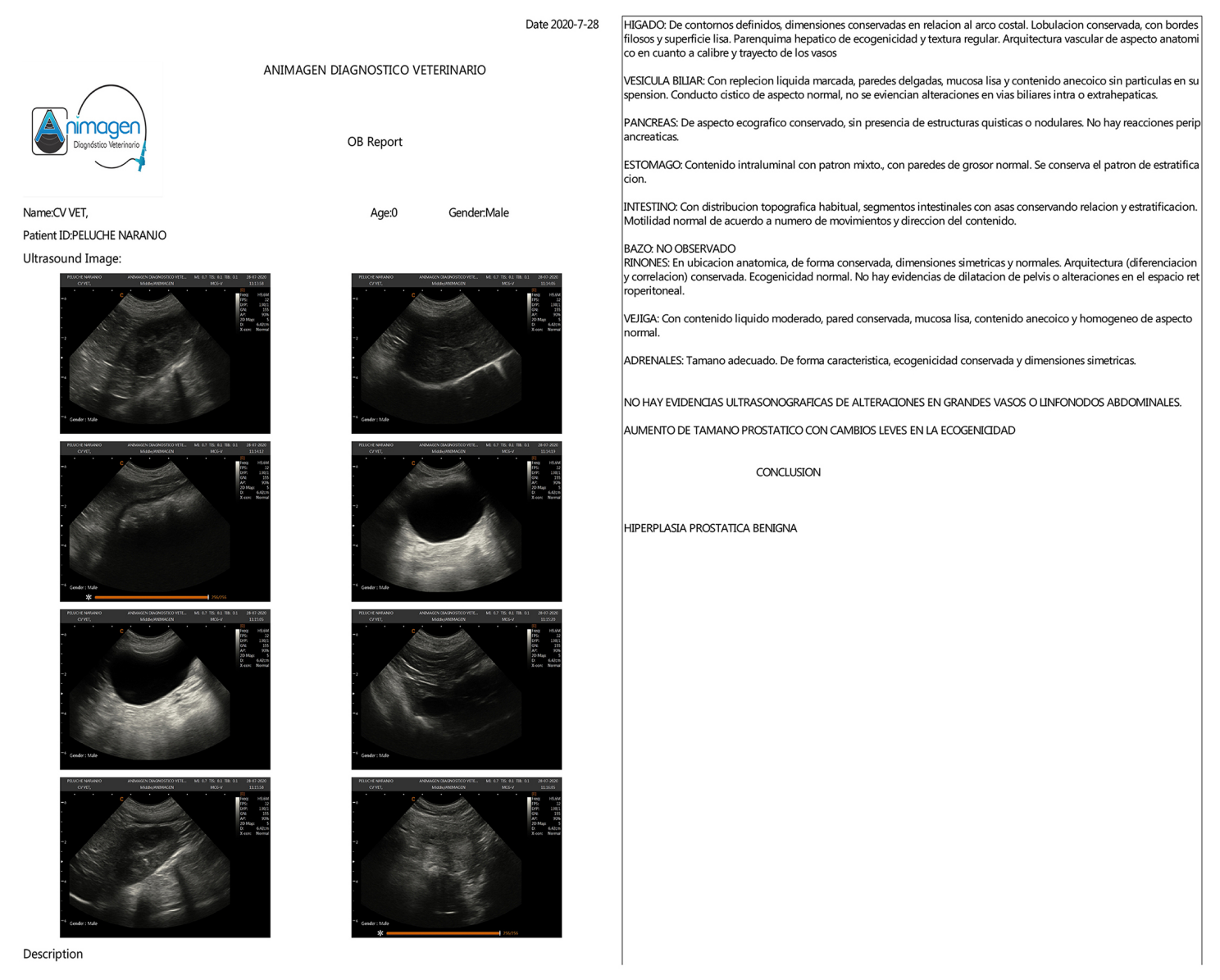

Figura 8. Descripción del informe ecográfico de abdomen donde se describe alteraciones en próstata, pero no se reportan hallazgos sugerentes de metástasis abdominal o compromiso de cadena ganglionar mesentérica. Ayuda diagnóstica realizada en otro centro veterinario de la ciudad de Medellín. 

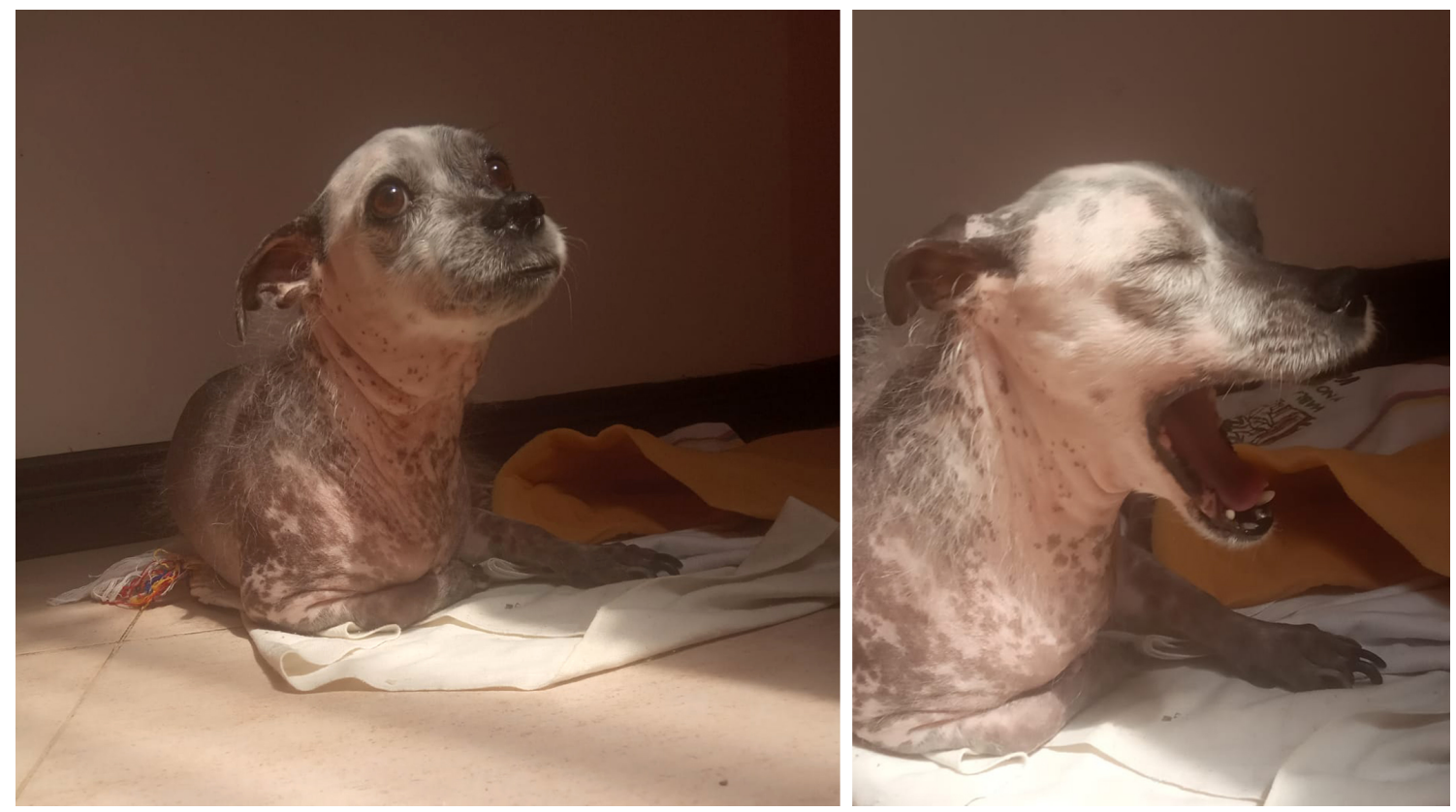

Figura 9. Paciente que sufre alteraciones gastroentéricas (vómito y diarrea), alopecia generalizada y pérdida de la capacidad visual después de ser sometido a quimioterapia. El paciente persiste con alteraciones sistémicas por casi cuatro meses, donde fue sometido a terapia convencional sin resultados favorables.
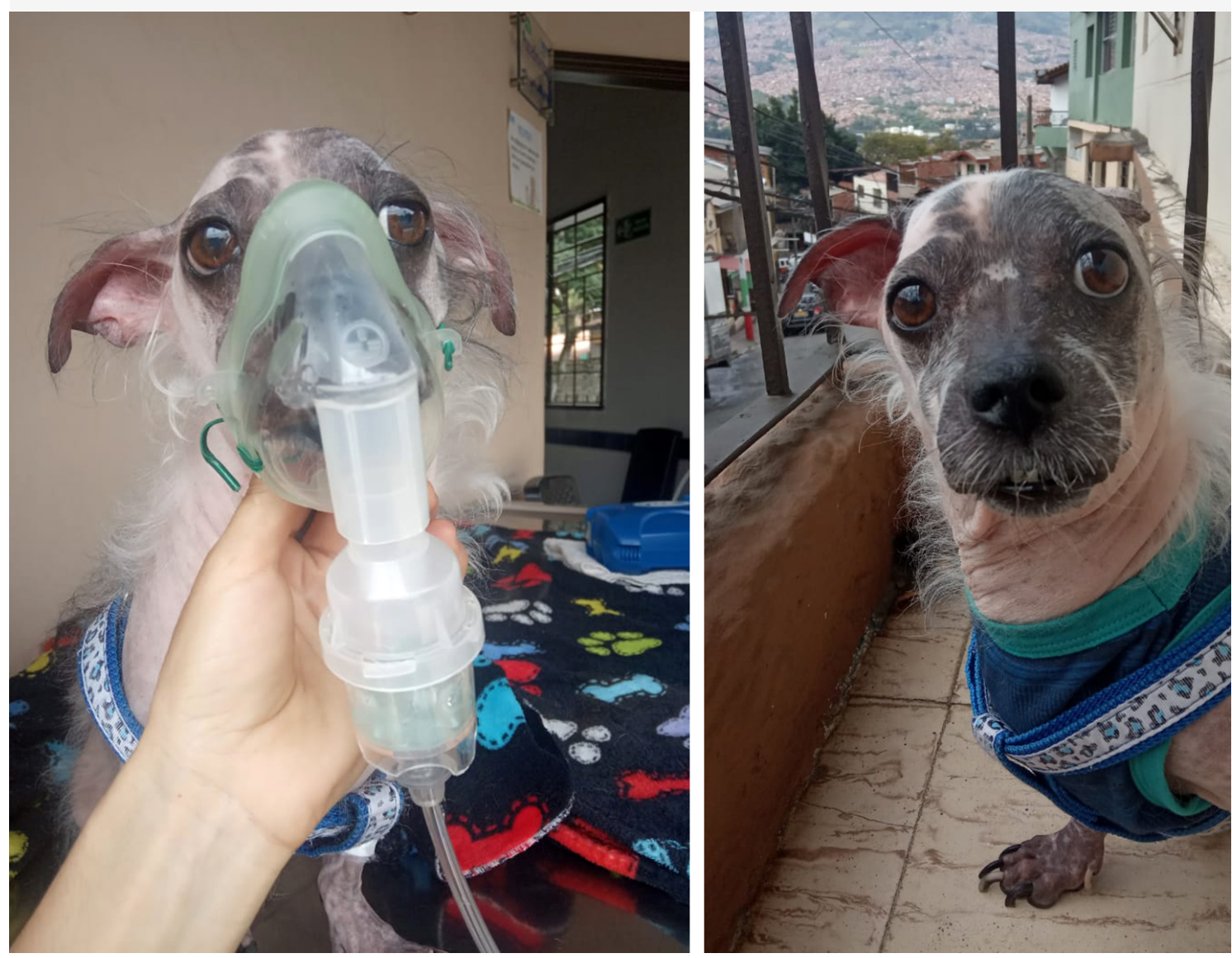

Figura 10. Ingreso al centro veterinario Juan Carlos Builes donde inicia terapia bio reguladora con nebulizaciones y sueroterapia. Se estimula el MALT por diferentes vías, acorde a los planteamientos de la medicina biorreguladora de sistemas: Multidosis, multivías y multiobjetivos. 

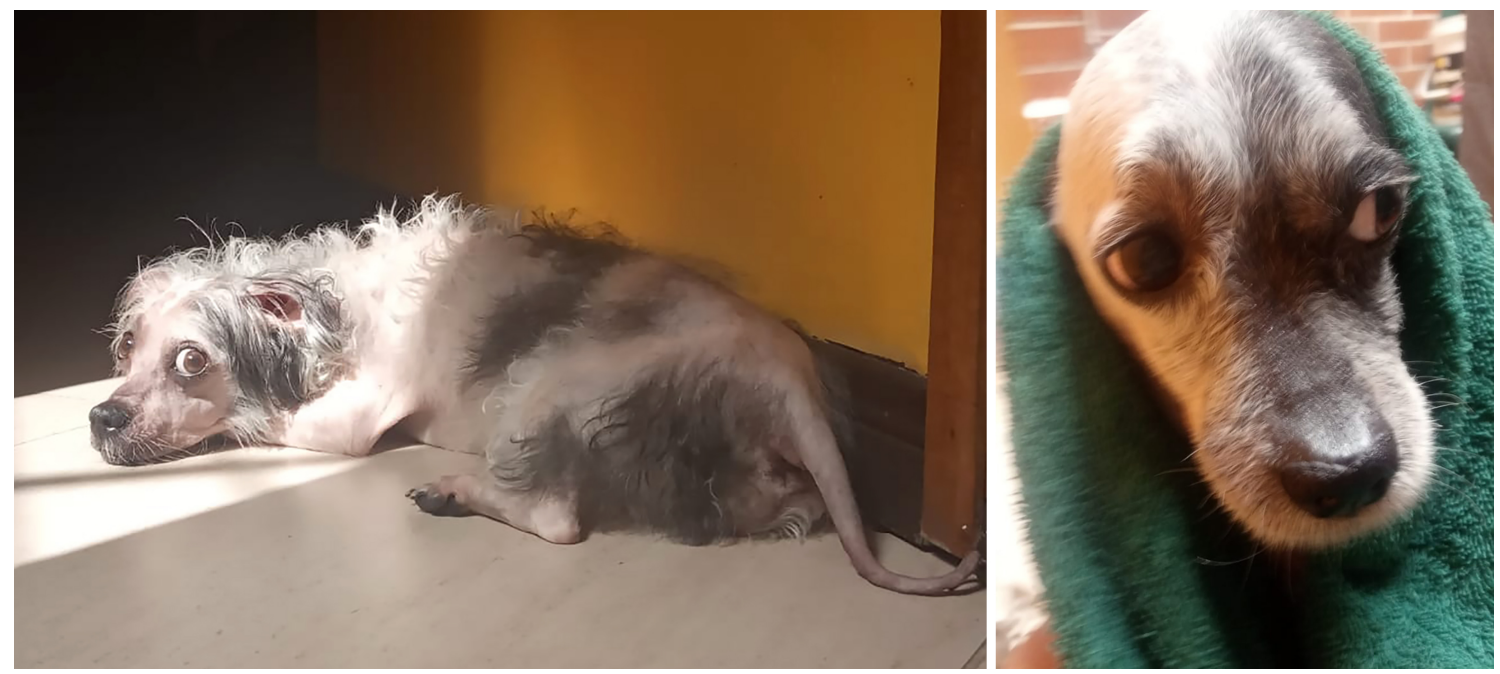

Figura 11. Paciente estable en sistema gastroenterológico pero persiste la alteración en tegumentario; se recupera la capacidad visual aunque persiste la inestabilidad emocional, está retraído y de apetito selectivo

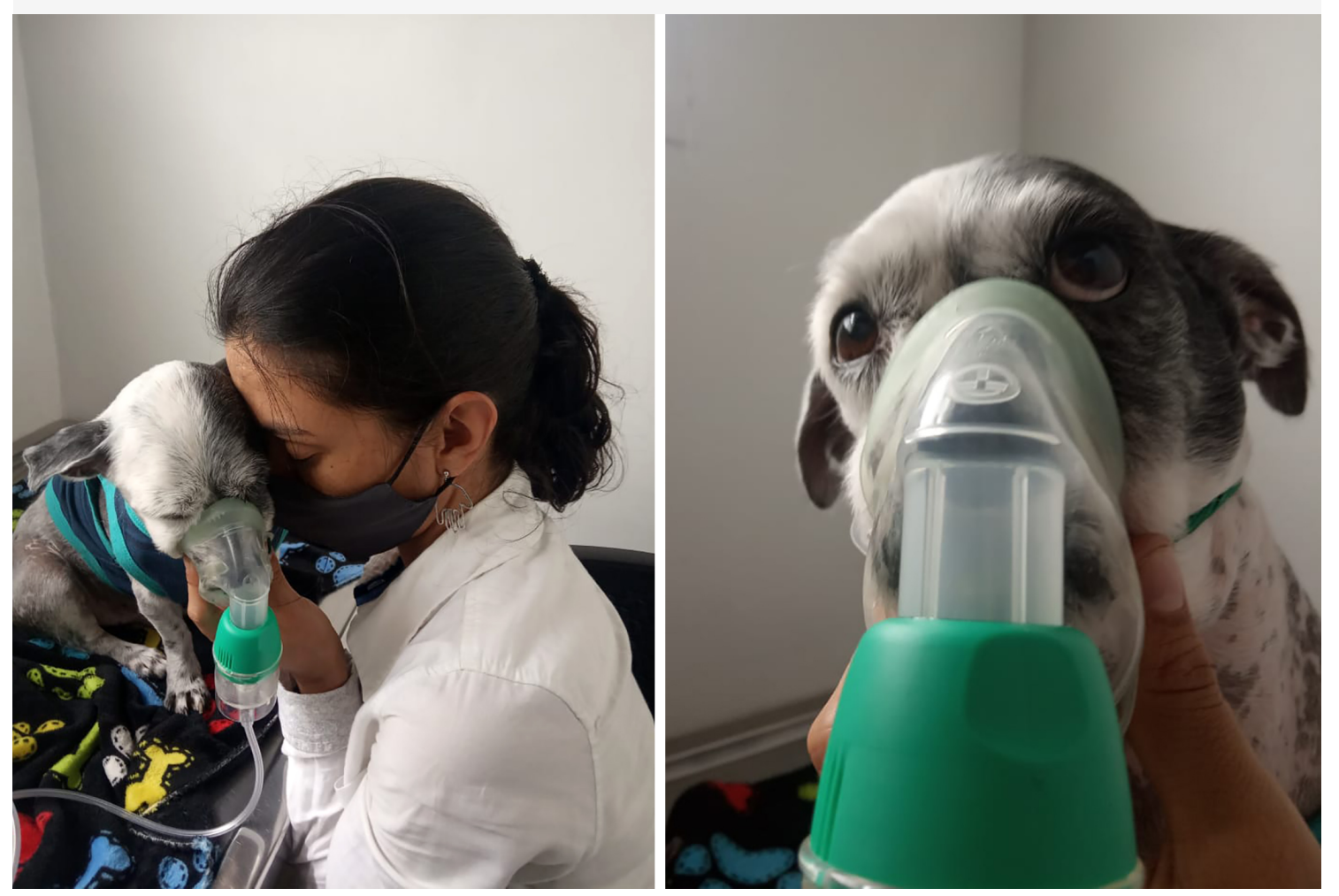

Figura 12. Se continúa con la terapia en centro veterinario Juan Carlos Builes con marcada mejoría en piel, donde se nota foliculogénesis inicial en diferentes áreas del cuerpo. Los procedimientos terapéuticos en el consultorio se realizan semanalmente por cuatro semanas y se instaura terapia en casa durante un mes inicialmente. 

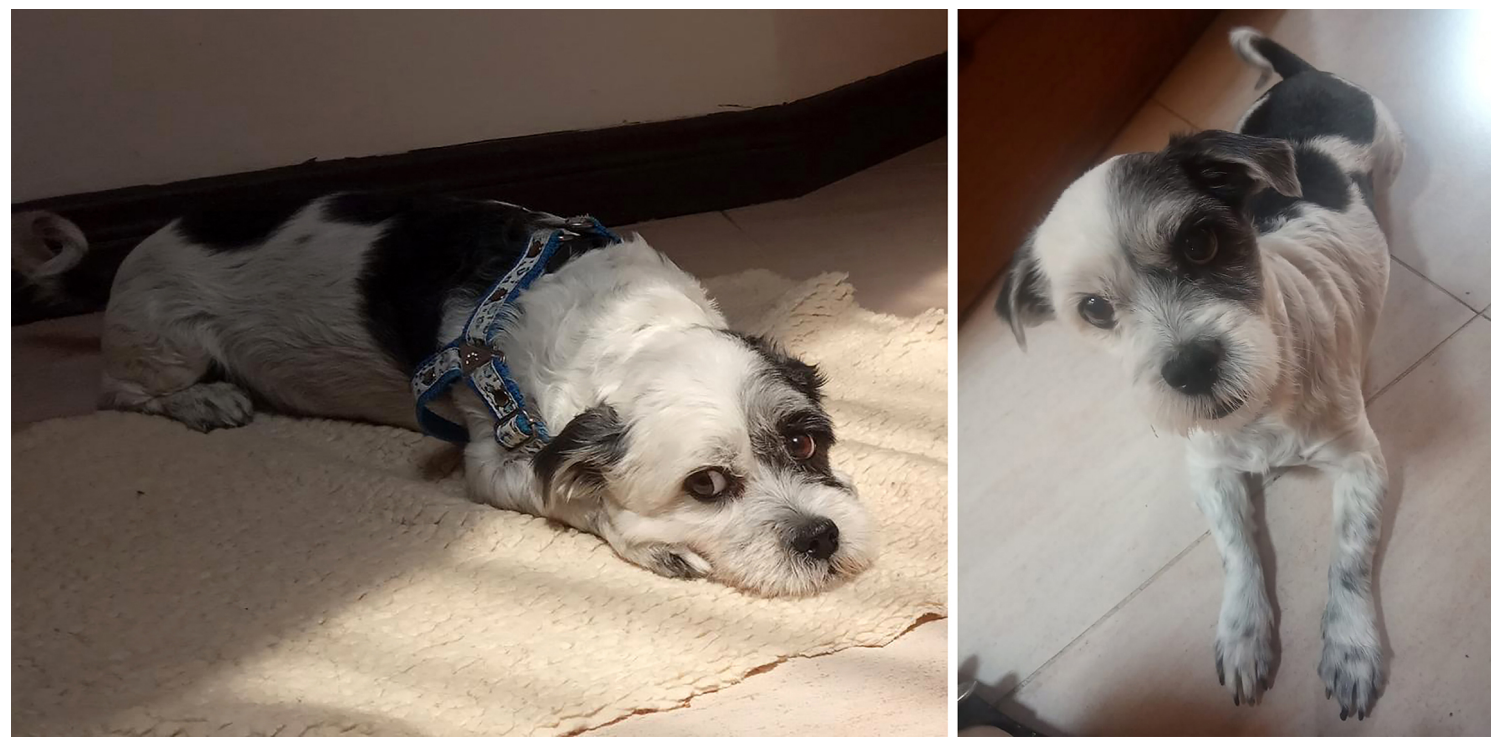

Figura 13. Marcada mejoría del sistema gastroentérico y tegumentario donde se nota foliculogénesis generalizada, ya no se nota decaído y su apetito ha mejorado completamente. Continúa con terapia en casa incluyendo simbióticos prescritos desde la primera semana de tratamiento.

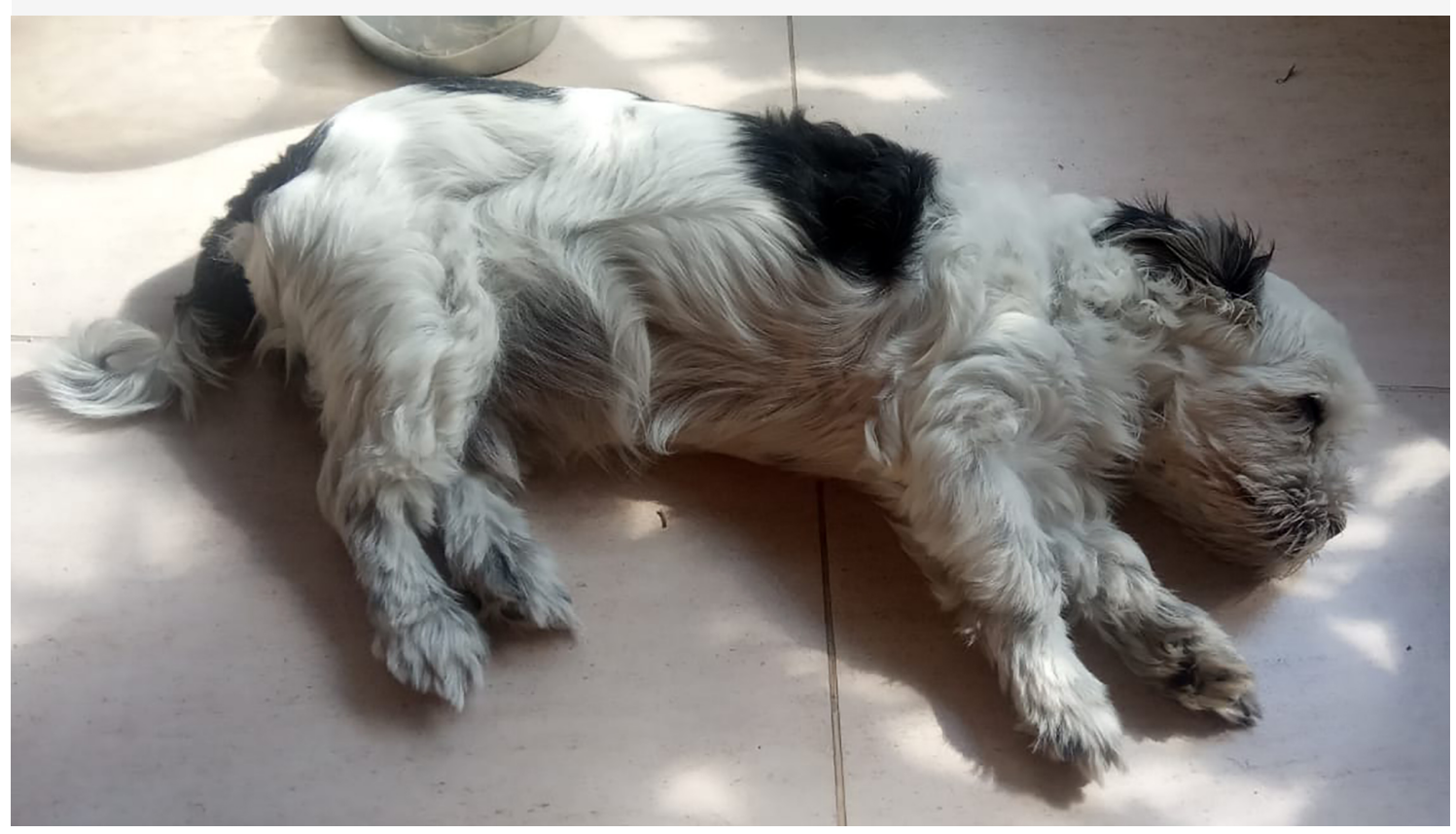

Figura 14. Paciente con unidad pilosebácea apocrina activa visible por crecimiento abundante de pelo primario y secundario lo que genera el manto y submanto fisiológico de la raza. Condición de piel adecuada para un paciente de 12 años, con una alimentación basada en concetrado comercial. 

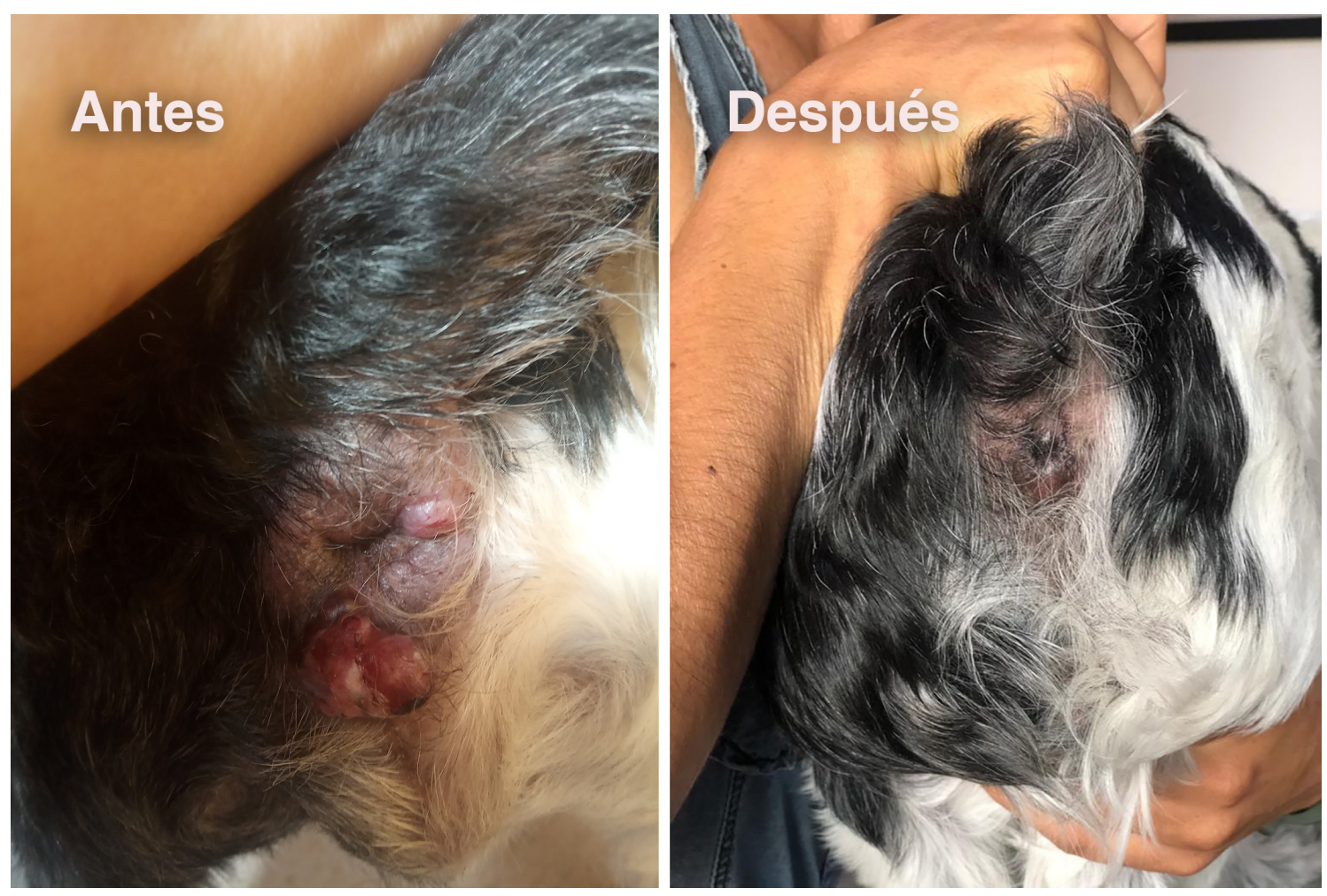

Figura 15. Comparación entre los hallazgos iniciales de la enfermedad con la condición actual del paciente, el cual no manifiesta sensación de dolor y se auto regula el proceso de auto lamido que genera la condición neoplásica. No presenta disquecia, tenesmo y se nota recuperación completa del área lesionada. Es una neoplasia auto regulada que no presenta recurrencias. 

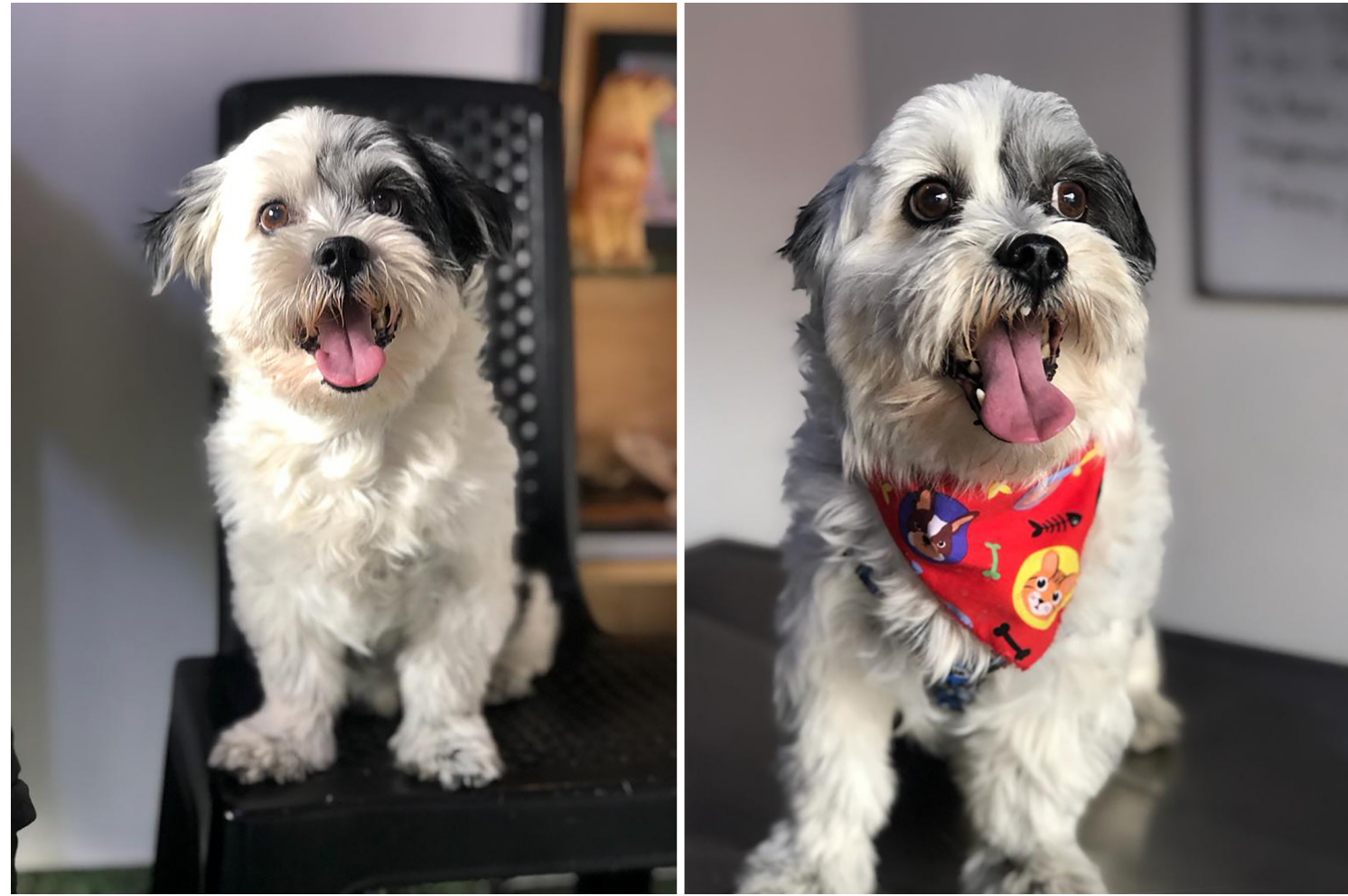

Figura 16. El paciente en el centro veterinario Juan Carlos Builes en revisión post terapia bio reguladora de sistemas con una condición física y emocional estable. La recuperación y estabilización inicial se presentó durante el primer mes, los siguientes dos meses fueron de valoraciones clínicas para un total de tres meses para su total recuperación y no recurrencia. 

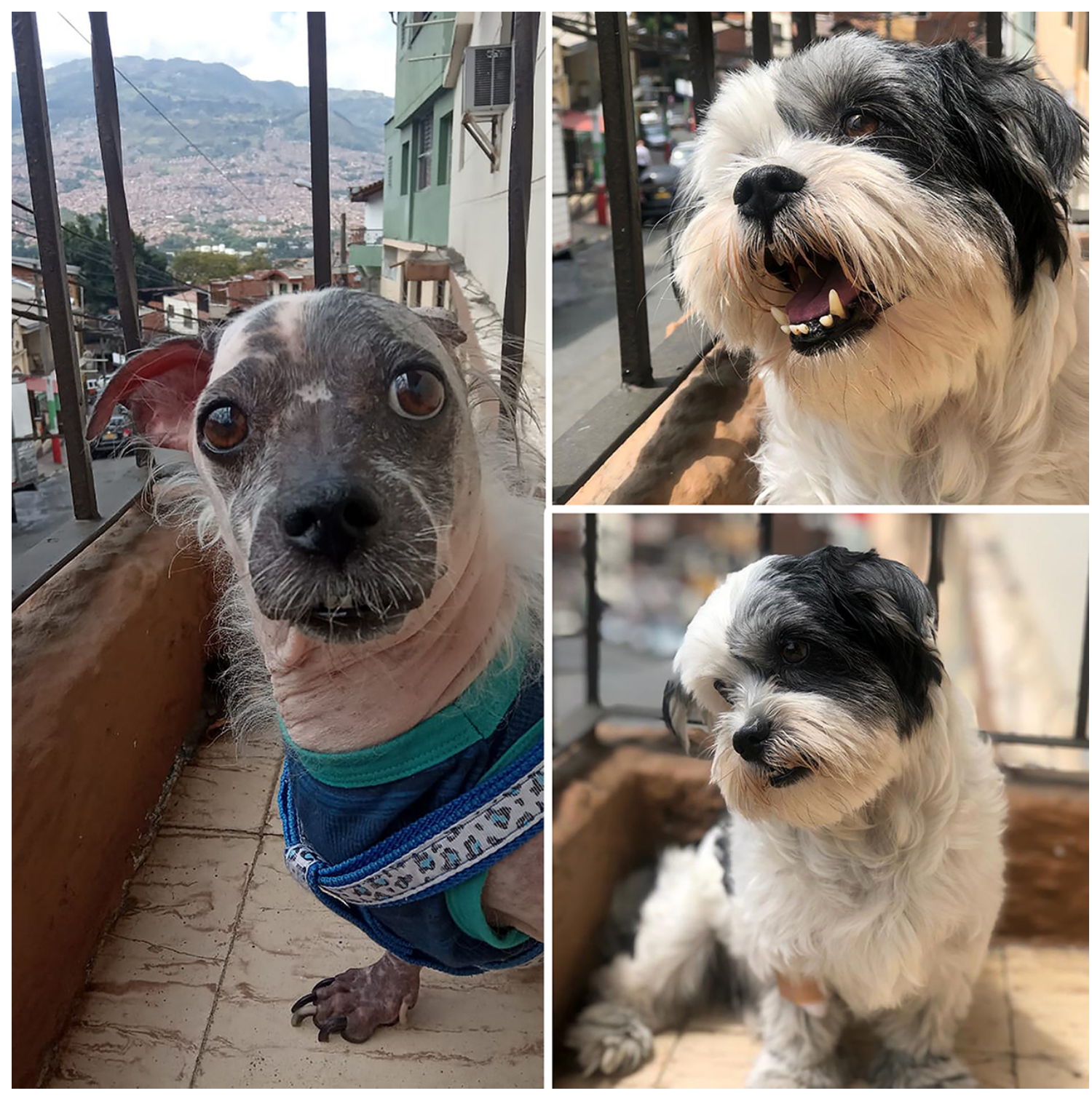

Figura 17. La resulómica es un factor importante de la medicina biorreguladora de sistemas, donde se nota como pacientes que presentan alto grado de complejidad clinica, pueden resolver satisfactoriamente aplicando los principios de la medicina de redes. Este caso muestra como desde la tabla de evolución de la enfermedad el sistema tiene la capacidad de retornar a la salud desde la desdiferenciación celular siempre y cuando se realicen los procedimientos terapéuticos bio reguladores acertados. 


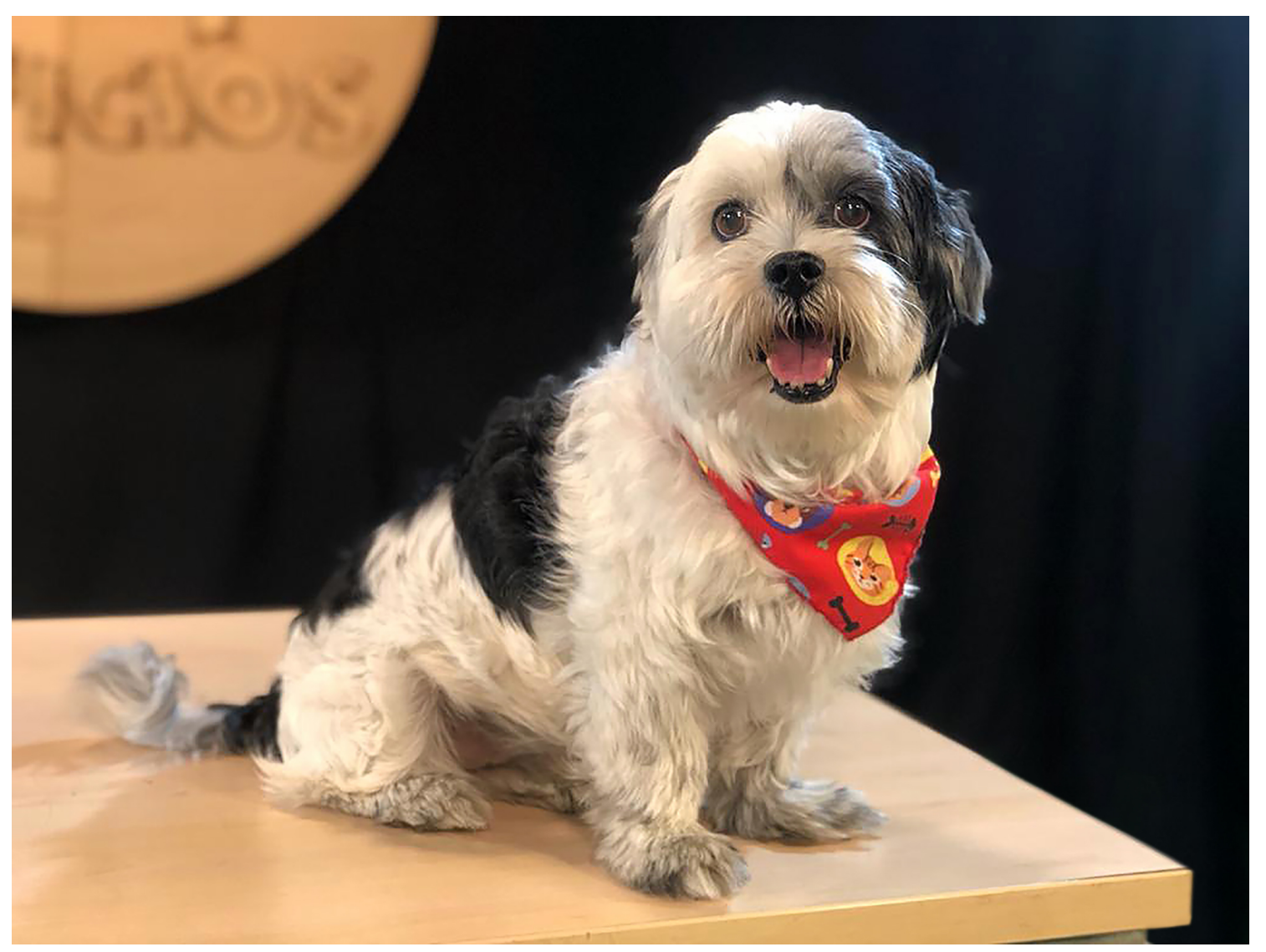

Figura 18. Al paciente es a quien se debe agradecer, ya que son eternos maestros y permanentemente estarán aportando conocimientos a los médicos veterinarios que están relacionados con la medicina bio reguladora de sistemas. Finalmente son los pacientes los protagonistas de la resolución del proceso morboso y los médicos facilitarán los procesos fisiológicos para que se presente la auto regulación y no recurrencia de la enfermedad. 